\title{
IMPORTANCIA DEL CO-LECTOR EN LA CULTURA ESCRITA
}

\begin{tabular}{c}
\hline Mario Amorós Terrones \\
Asociación Peruana de Lectura \\
\hline
\end{tabular}

De pronto me encontré leyendo cuentos en voz alta a mis abijados, antes de acostarse. ¡Eran tan pequeños! No sabian leer, pero ya poseían libros. No podian procesar las letras, pero les sobraba curiosidad para comprender. Yo les comentaba la portada, el título, los colores, los dibujos... y les hacia preguntas. Cultivaba su complicidad y su motivación con el diálogo, con mis preguntas insistentes. Leía cada fragmento como si fuera un actor en el escenario, marcando los silencios, esperando sus risas, una onomatopeya o unas carcajadas. Me escuchan en silencio, atentos, activos, inquietos, durante mucho rato, mirándome a mi y a las ilustraciones, pero también siguiendo las letras

Daniel Cassany (2007)

Fecha de recepción: septiembre de 2012 Fecha de aceptación: octubre de 2012

RESUMEN: En este trabajo el autor se centrará en la figura del co-lector: las persona que anima, estimula, promueve y acompaña a un semejante (usualmente menor) para su apropiación adecuada de la cultura escrita; esto es, en la adquisición de la lectoescritura. El tema propuesto está validado por experiencias aplicadas en infantes de educación inicial y del primer grado de educación primaria, tanto de la sierra como de la costa peruana. A partir

* Mario Amorós Terrones es especialista de la Dirección de Desarrollo de Instituciones Educativas (DIGEDIE) del Ministerio de Educación de Perú. Ha sido Presidente de la Asociación Peruana de Lectura (APLEC) y Director Pedagógico del Consorcio de Centros Educativos Católicos del Perú. 
de la ejecución del proyecto "Lee conmigo», cuyo propósito es promover la cultura escrita en niños que aún no han sido alfabetizados, el autor analiza la importancia de la integración de tres elementos en la práctica de la lectoescritura: la familia, la escuela y la comunidad; en otras palabras: los padres, los docentes y el texto.

Palabras clave: lectura, educación, lectoescritura, cultura escrita, escuela, familia, docente, comunidad.

ABSTRACT: In this paper the author will focus on the figure of the co-reader: the person who encourages, stimulates, promotes and accompanies a fellow (usually younger) for adequate appropriation of the written culture, that is, the acquisition of literacy skills. The proposed issue is validated by experiences in kindergarten infants and first graders in primary education, both in the highlands and the Peruvian coast Based on the project «Read With Me», whose purpose is to promote the written culture in children who have not been taught to read and write yet, the author discusses the importance of the integration of three elements in the practice of literacy: the family, the school and the community; that is to say, parents, teachers and the text.

KeYwords: reading, education, literacy, written cultures, school, family, teachers, community.

\section{EL RETO: FORMACIÓN DE LECTORES}

O dice que para formar un lector «hay que hacerlo 20 años antes de que nazca». Aunque parezca exagerado, en el fondo se alude la necesidad de tener padres lectores porque ellos son los primeros responsables de la estimulación hacia la lectura. Ya es tarde si se piensa que 
el niño debe entrar a la escuela para «aprender a leer». Y es que el proceso de la lectura, al igual que el proceso del habla se inicia tal vez desde el momento que empieza la vida, en el seno materno o por lo menos desde el nacimiento. Así como la madre "comenzó a hablar a su hijo sin que este sepa el idioma» ¿por qué no leerle en voz alta desde el inicio?

Quizá es cuestión de que los padres entiendan que, por muy ocupados que estén, el alimento más importante que pueden dar a sus hijos, después de las caricias, es el leerles en voz alta. Múltiples experiencias refuerzan esta teoría y no falta quien declare: «les leí a mis hijos porque mi padre, a su vez, me leyó a mí», y tal vez agregue: «quería que ellos disfrutaran tanto como yo había disfrutado». Y es que, como dice Jim Trelease: ${ }^{1}$ «leer a los niños les ayuda a ampliar su vocabulario, estimula su imaginación, prolonga el lapso de su atención, fomenta el desarrollo emocional y los introduce a las estructuras y matices de la lengua».

Aparte de que el niño va estimulándose hacia la lectura en el ambiente natural de la familia, también podría obtenerse algunas otras ventajas. Estas son el acercamiento cálido al libro, la construcción del hábito lector, el mejoramiento de la comunicación en la familia, la visita a librerías o ferias de libros en búsqueda del material adecuado, la posibilidad de recrear lo leído con juegos y otras actividades, etc. Así pues, otorgar a los hijos unos cuantos minutos al día, muy gratos por cierto, leyéndoles algo, es darles un regalo para toda la vida.

1 Jim Trelease es periodista y escritor americano, conocido a nivel internacional por su libro Manual de la lectura en voz alta, en el que potencia la voluntad lectora asociándola también a la lectura común y en viva voz. El libro se ha publicado en prácticamente todo el mundo y ha sufrido múltiples reediciones a la vez que se ha ido adecuando al paso de los años. 
Los niños empiezan a aprender a leer y escribir bastante antes de llegar a la escuela. En sus casa, en la calle, [en el mercado], descubren diversos artefactos (libros, carteles, etiquetas,) que contienen letras [textos escritos]. Ven a las personas que leen y escriben y se dan cuenta que de que ésas son tareas relevantes. (Aliagas Marin 2009)

Cristina Aliagas, quien vivió la experiencia de atender como una "canguro» ${ }^{2}$ a Litang, niña china de 3 años, con un dominio incipiente del catalán al inicio y con resultados exitosos después de su intervención como co-lectora, nos propone algunos ejes de la formación lectora:

a) La integración de la práctica lectora en espacios naturales. En la escuela, la lectura obedece a una disciplina estricta, con prácticas obligadas que pueden generar satisfacciones o frustraciones. En los espacios no escolares (como la casa), la lectura puede funcionar como un juego o un pasatiempo fugaz y contribuye poderosamente a consolidar el hábito lector.

b) La dimensión humana en la práctica lectora. La lectura en casa, la lectura cumple una función más personal y singular (relación con el mediador) y no está sujeta a normas (no es una cosa rígida) aunque sí podría establecerse o negociarse un ambiente y el momento diario más o menos fijo para la práctica lectora.

c) La figura del co-lector. La persona o personas que van a tener a su cargo el acompañamiento al lector aprendiz. Idealmente deberían ser los padres, los dos a la vez o uno de ellos o en todo caso un abuelito, un

2 Denominación que se usa para referirse a la persona que se encarga de cuidar a una criatura. Una especie de niñera o institutriz. 
tío... En esta interacción niño-adulto se negocian significados verbales, literarios y socioculturales que promueven su crecimiento cognitivo como lectores y miembros de una comunidad.

«El co-lector es más que aquel lector particular que oraliza textos y media la textualidad: es más bien un colaborador o aliado con quien los niños dialogan sobre sus cuentos, sus experiencias de vida y sobre el mundo» (Aliagas 2009).

d) La lectura compartida, una experiencia más. La lectura compartida es una manera distinta de leer y requiere de un espacio social interactivo construido entre al menos dos personas. No es una formación suplementaria a la que se brinda en la escuela sino más bien una experiencia significativa en la vida lectora de cada niño.

e) La imbricación de la experiencia vital con la literaria. Los libros infantiles pueden transformarse en espacios de experiencia y conocimiento, cuando coinciden con las aptitudes y necesidades auténticas de los niños. Los protagonistas de los cuentos se convierten en ídolos con los que se comparten y resuelven los miedos y las fatalidades. Así aprenden muchos niños a compartir sus juguetes, a dormir con la luz apagada, a comer solos e incluso a comportarse en una biblioteca.

Desde hace años atrás, un artículo de la famosa revista Reader's Digest, llamó poderosamente mi atención; no solamente por el título, sino por el protagonista (Jim Trelease), quien sin ser docente promovió la práctica de leer a los niños desde la más tierna edad. Esto se ha concretizado en algunos lugares de tal forma los padres de familia firman un compromiso de leer a sus hijos en casa.

En esta oportunidad vamos a enfatizar el tema referente a las personas que animan, estimulan promueven y acompañan a un semejante 
(usualmente menor) para su apropiación adecuada de la cultura escrita; esto es, hablar de co-lectores y su importancia en la adquisición de la lectoescritura. El tema está validado por experiencias aplicadas con infantes de educación inicial y el primer grado de educación primaria tanto de la sierra como de la costa.

\section{PROYECTO «LEE CONMIGO»}

El Proyecto «Lee conmigo» (en adelante PLC) tiene como propósito promover la cultura escrita en niños que aún no han sido alfabetizados. Para ello se propone la integración de tres elementos: la familia, la escuela y la comunidad; en otras palabras, los padres, los docentes y el texto.

Uno de los fundamentos teóricos en el que se basa esta experiencia es la propuesta de Vigotsky, quien asegura que en todo proceso educativo debe haber una estrecha relación y colaboración entre adulto y niño. La Zona de Desarrollo Próximo (ZDP) es la distancia entre el nivel real de desarrollo (capacidad de resolver un problema, en forma independiente) y el nivel de desarrollo potencial (resolución de un problema bajo la guía de un adulto, o en colaboración con un compañero más eficaz). Asimismo, sostiene que todo aprendizaje es un fenómeno social, ya que los procesos evolutivos internos operan solamente cuando el niño está en interacción y en cooperación con sus semejantes.

\section{Intervención del co-lector}

El co-lector es la persona (generalmente adulta) que acompaña al futuro lector en la formación de su cultura escrita. Si bien los padres les señalan y leen a los niños los carteles escritos, lo que más favorece a la adquisición del lenguaje escrito es la lectura frecuente de cuentos. 
Cuando el co-lector lee un cuento en voz alta a un niño produce cambios en la entonación, caracteriza un personaje, crea suspenso, mantiene la atención, genera un intercambio verbal alrededor de la historia, etc. También se promueven estrategias de comprensión de textos, que contribuyen al aprendizaje de la lectura.

Asimismo, en la lectura frecuente de cuentos es fundamental la forma en que el co-lector mediatiza el texto. Con ello se contribuye al desarrollo del vocabulario, a la adquisición de conocimientos sobre el libro y su manejo, a la orientación de la escritura, al reconocimiento de palabras escritas y el desarrollo del esquema narrativo.

Si fuéramos sensatos, el paradigma del aprendizaje del lenguaje hablado debe constituir también el modelo para la enseñanza y el aprendizaje de la lectura. Si el niño no escucha que las personas hablan en su casa es seguro que no hablaría con presteza. ¿Cómo pretender que lea sin que tenga estímulos, materiales, tiempos disponibles y ejemplos al interior de su hogar para recrearse con los libros que es práctica mágica y hasta sublime?

Igualmente, si no descubre las figuras e inscripciones sencillas en todo soporte, si no hojea las páginas de los libros, difícilmente adoptará la lectura de manera sincera y eminente. Para desarrollar adecuadamente la lectura es importante considerar entonces el rol de la familia y del contexto, conformado hasta por el vecindario y la misma ciudad.

\section{1. Participación de la familia}

El PLC se genera desde la escuela para comprometer la participación activa de los padres en la estimulación de sus hijos en la lectura. Esto no es novedad ya que se aplica formalmente en los países desarrollados; sin embargo en nuestro país hay que «romper el paradigma de que para aprender a leer hay que ir a la escuela» sin tener en cuenta que los procesos de comunicación 
(hablar, escuchar, leer y escribir) se desarrollan en forma natural desde el inicio de la vida. Si a un niño nunca se le hablara, nunca aprendería a hablar porque a hablar se aprende hablando. Esto también es aplicable para las otras capacidades comunicativas.

En el caso propiamente de la lectura, muchos autores, coinciden en señalar que «cuando a los niños se les lee regularmente desde muy temprano en su vida, pronto comienzan a demostrar un creciente goce en la experiencia. Su rango de atención aumenta, su repertorio de cuentos favoritos se expande, y ellos comienzan a pedir que se les lea una y otra vez» (Alliende y Condemarín 2002).

Solo el 36\% del aprendizaje del alumno puede ser atribuido a la escuela (Mc Donald, 1976), los otros dos tercios del conocimiento del niño son obtenidos del hogar y de la comunidad. Las diversas investigaciones (Nicholson 1980, Durkin 1981, McKunney 1976, Raim 1980, etc.) sobre el papel de la familia en el aprendizaje de la lectura, permiten afirmar que:

a) El educador debe sacar el máximo provecho de los recursos que le puede brindar la familia y la comunidad.

b) Muchos padres se sienten motivados para colaborar con los maestros en la estimulación de la lectura de sus hijos, pero requieren orientación sobre cómo hacerlo para que ayuda sea efectiva.

c) La mayoría de los buenos lectores y lectores precoces provienen de hogares donde los padres son modelos (son lectores) que estimulan sus experiencias y les proporcionan materiales de lectura. Los padres son los primeros interesados en la alfabetización oportuna y adecuada de sus hijos; por lo que deberían poner todos sus esfuerzos para que sus hijos tengan el acercamiento más agradable al mundo de la lectura y sobre todo ellos tendrán la obligación de proveerle de los más variados materiales de lectura. 


\section{Importancia de los padres en función de co-lectores}

¿Cada cuánto tiempo leen los padres cuentos o historias a sus hijos?, ¿cada día?, ¿una vez a la semana?, ¿una vez al mes?, ¿lo han hecho alguna vez? La lectura infantil es muy importante para el desarrollo de un niño. La lectura es de vital importancia, ya que juega un papel clave en el desarrollo emocional, cognitivo y social del niño. De hecho, la lectura en voz alta de cuentos infantiles es una de las actividades más importantes que nosotros, como padres, abuelos o profesores, podemos hacer por nuestros niños.

Si una madre (o un padre) ya lee con frecuencia a su bebé o a su niño, debe sentirse orgullosa, ya que entiende los beneficios que la lectura tendrá en su desarrollo intelectual y personal. Si todavía no lee libros a sus hijos, deberá convencerse acerca de lo positivo que es la lectura y deberá empezar lo antes posible.

Lo más importante es que no se busque excusas ya que cualquiera puede leer historias a sus hijos. No se tiene que ser experto, científico, o profesor; solo se tiene que querer vivir esta experiencia tan especial con los hijos y tener la sensibilidad de disfrutar de un momento tan especial. Un acto tan simple como leerles historias, generará un vínculo importantísimo con los pequeños que no se debiera desaprovechar.

El simple acto de leer cuentos infantiles a nuestros hijos puede ser determinante en su desarrollo intelectual y personal, ya que consigue que el niño se sienta más querido y que se aficione a la lectura, incrementando así su probabilidad de éxito. 
¿Cómo estimular la lectura en casa?

Para estimular la lectura desde el hogar y basándonos en Mary Mc Donnell (1981) sugerimos al padre/madre o co-lector tener en cuenta lo siguiente:

- A través de los juegos y conversaciones de los niños se pueden identificar sus intereses los cuales se pueden implementar con material de lectura. Si una niña se interesa por la jardinería, se le puede proporcionar libros, revistas folletos sobre este tema.

- Será muy estimulante armar o pintar el estante de libros con el apoyo de los propios niños. Del mismo modo el forrar los libros de distinto color según el tema.

- La biblioteca personal del niño permitirá tener sus libros al alcance de la mano y su implementación puede ser progresiva; sin embargo, no debe faltar un buen diccionario, libros de consulta incluyendo uno de mapas (Atlas), revistas, etc. El niño se sentirá orgulloso de mostrar su biblioteca y sobre todo de mejorarla con el apoyo de amigos y familiares mediante el obsequio de libros.

- Se puede crear en la casa algún sector de lectura en la que los niños puedan leer placenteramente (sentados o echados). Esto implica un espacio donde exista la menor posibilidad de perturbaciones o distractores, luz apropiada, algunos muebles mínimos (estante, mesa, silla), alfombra o equivalente (según la región), cojines, etc.

- Los padres deben habituar a sus hijos a visitar librerías, bibliotecas y ferias de libros; asistir a presentaciones de libros (vinculados a su edad o interés); dialogar con libreros, bibliotecarios, autores; hojear libros (pueden despertarles nuevos intereses).

- Los padres deben leer en sus momentos libres delante de sus hijos y comentarles lo leído. Los niños deben sentir que los adultos disfrutan de la lectura y que el tiempo invertido en ella vale la pena. 
- Los padres deben leerles a sus hijos desde pequeños. Haría muy bien la madre en estado de gestación le lea en voz alta a su hijo que está aún en su vientre; lo estará iniciando en el mundo de la lectura. Las lecturas de relatos, canciones o poemas en voz alta y si fuera posible dramatizando, constituyen un recuerdo altamente emotivo y significativo.

- A veces bastará que los padres acompañen a su hijo durante el momento de su lectura. Pueden presentarse diversas modalidades como leer juntos o alternándose, leer primero en silencio y luego a viva voz, «leer» primero los gráficos y luego los textos, etc.

- Los padres deben informar a los maestros sobre el nivel de interés o de rechazo que sus hijos manifiestan por los libros en general o por los libros recomendados por los mismos docentes.

- Los padres pueden sugerir a los maestros libros con los cuales han tenido una buena experiencia. Se podría establecer entre los compañeros de clase una especie de banco de libro en el que sistemáticamente todos se puedan prestar los diversos libros que cada familia posea.

- Los padres podrían prestar trabajo voluntario para ayudar al maestro en actividades de lectura. La presencia de padres voluntarios en el aula o que reciben en su casa a un compañerito de sus hijos, le proporciona al niño una oportunidad para aprender nuevas destrezas y una motivación que no la encontró en su casa.

- Ya que es imposible tener una biblioteca familiar completa y actualizada por lo costoso que resulta, los padres deben ser los más interesados en promover que la biblioteca de la escuela brinde un servicio de calidad con: material adecuado, suficiente y actualizado, sala de lectura (individual y grupal), horario amplio, sistema de préstamo a domicilio, atención a cargo de bibliotecólogos o de personal capacitado, etc. 
- Visitar la biblioteca municipal o de su comunidad, sacar el carné de socio y utilizar el servicio de préstamo de libros.

- Los padres deben apoyar y participar en las actividades del Plan Lector que la escuela haya organizado.

- Los padres que puedan contar con equipos audiovisuales podrían aprovecharlos para estimular la lectura. Así por ejemplo con el karaoke pueden leer canciones, las películas con texto permiten ejercitar la lectura, etc. Lo ideal sería que se convierta a la TV en una gran promotora de la lectura.

- Las redes computacionales, como Internet también constituyen un excelente medio para estimular la lectura: los correos electrónicos, el chateo y la inmensa información que se puede encontrar a través de los buscadores.

- Lo más importante, es que los padres establezcan un clima emocional que favorezca la lectura de sus hijos. Ya no funciona la simple orden o mandato para que el hijo lea. Menos aún se debe utilizar el grito, la amenaza, el chantaje o el castigo. Lo que da muy buen resultado es el dar ánimo, reconocer los avances y logros, el tolerar sus limitaciones, el premiar sus iniciativas de leer por propia cuenta, etc.

El PLC tiene como estrategia inicial el de sensibilizar a los padres de familia respecto a un nuevo rol que pretende hacerlos protagonistas de uno de los aprendizajes más importantes para el niño: la lectura. En tal sentido, se informa a los padres respecto a los avances científicos que existe respecto a la adquisición de la lectura, así como de las amenazas y dificultades que podrían presentarse y para lo cual hay necesidad de establecer estrategias adecuadas y prevenir las situaciones desventajosas. 
Sin embargo, los padres requieren de técnicas para afrontar con éxito la experiencia por lo que es necesario implementar talleres que tengan que ver con aspectos relacionado al cuándo, cuánto, dónde y el cómo leerle a su hijo adecuadamente.

Los niños y las niñas tienen la mala costumbre de no pedir permiso para empezar a aprender.

(Emilia Ferreiro)

Escuchar cuentos en la escuela, en el parque, en la biblioteca y aunque sea por un buen cuentacuentos, como dice Cullinan, B. (1992) no puede compararse con los cuentos leídos en voz alta por su propia madre o padre porque cuando un padre le lee a su hijo le está enseñando más allá del material de lectura. Es como si le estuviera afirmando: «Tú eres importante para mí. Aquí estás sano y salvo; yo siempre te protegeré, nosotros hacemos cosas juntos, en familia, que son divertidas, sanas y valen la pena».

\section{Puede que tengas riquezas muchas,}

cofres con oro y estuches con sortijas.

Pero más rico que yo jamás serás,

Porque tuve una madre que me leía.

(Strickland Gilligan)

\section{2. Participación de la comunidad}

El Proyecto LC también compromete a la comunidad. Es en ella donde vamos a encontrar lo que los padres van a leer a sus hijos: los libros. En nuestro medio ya existe una suficiente oferta de material lector sobre todo en las urbes; sin embargo, el acceso a estos productos intelectuales aún es elitista y solo privilegia a los sectores económicos altos. 
Una buena política del MED es la de entregar textos a las escuelas públicas aunque a veces es todavía insuficiente o falta capacitar a los maestros sobre su uso. Lamentablemente la escuela privada no tiene este privilegio y el costo de los materiales bibliográficos los tiene que asumir los padres de familia.

Si bien es cierto que hoy hay más libros pero la población poco a poco está formando una cultura de consumo de este bien. Han ayudado mucho en esto las ferias locales, nacionales e internacionales del libro, la aparición tenue de nuevas librerías y últimamente la celebrada noticia del otorgamiento del Premio Nobel de Literatura 2010, a nuestro compatriota Mario Vargas Llosa, ha permitido incrementar la venta de libros.

En cuanto a la responsabilidad que le compete a la comunidad debemos tener en cuenta sus características geográficas, sociales, culturales, etc. No sólo debemos ver si es que existe un acceso a la cultura escrita sino también la debida promoción y estímulo hacia la lectura mediante programas adecuados formulados por el gobierno local, los medios de comunicación social, las organizaciones de la sociedad civil, las ONG, etc.

Por ejemplo, si la comunidad donde vive el niño se encuentra en un ambiente citadino posiblemente habrá muchos textos (rótulos, letreros, avisos, nombres de instituciones, de calles y sobre todo, el acceso a periódicos, revistas, libros, etc.). Sin embargo, en las zonas rurales esta situación es adversa existiendo una gran ausencia de lo escrito, lo cual se agrava cuando la comunidad tiene como lengua materna el quechua, aymara o cualquier otro idioma nativo.

Ante esta falta de equidad en el acceso a la cultura escrita, una buena política del libro y de la lectura debería ser promover la creación obligatoria de centros de recursos educativos en cada una de las comunidades (caseríos) donde suele existir una escuela unitaria o unidocente. En este centro, 
indudablemente deberá instalarse una biblioteca a la cual deberían tener acceso no sólo los niños sino también todos los miembros de la comunidad.

El Proyecto LC contempla la obligación de los padres para adquirir los materiales de lectura que la tutora haya recomendado de acuerdo a criterios técnicos pedagógicos como la edad de los niños, los contenidos y las características físicas como tamaño (preferentemente grande), material (resistente), presentación (a todo color), contenido (preferentemente relatos tipo cuentos o fábulas de corta extensión, mucha ilustración y textos cortos con expresiones o palabras reiterativas), etc.

Para tal fin, se sugirió que los padres se organicen y una comisión se encargaría de comprar los libros (previamente seleccionados) para todos los niños. Los libros serían entregados a los padres de familia a fin de que los lleven a casa para que hagan la lectura a sus niños según el programa que la profesora les alcance. Dicho programa, se establece de acuerdo al desarrollo curricular del grado o año de estudios que cursa el niño.

Durante la capacitación de los padres, se les orienta respecto a la forma cómo se hará la entrega de los libros en casa. Se sugiere que la entrega tenga el sentido de un buen regalo por lo que interesa mucho la forma y el momento adecuado. Después hay que ayudar al niño a forrar su libro, ponerle una etiqueta con el nombre del niño, etc.

El libro es un puente entre el alma del escritor y la sensibilidad de un lector. Lo que he leido me ha enseñado a ver la realidad.

No nos queda más que repetirlo y proclamarlo. Leer humaniza. Andrés Amorós (español). 


\subsection{Participación de la escuela}

En el Proyecto LC, la escuela está representada a través de la tutora. Sus funciones son las siguientes:

a) Junto al Coordinador, planifica y ejecuta el Programa de sensibilización donde se motiva e informa a los padres de familia las bondades del proyecto.

b) Elabora el Programa de Lectura y se los hace llegar a los padres de familia para que ellos sepan cual de los libros tiene que leer a su hijo.

c) Propone o sugiere los materiales de lectura. En la experiencia se usaron 10 cuentos de la colección «Viajerito» de Ediciones Bruño.

d) La función más importante es la de consolidación de los aprendizajes. Esto quiere decir, verificar la comprensión lectora de sus niños a través de actividades como dibujos, modelados, escenificaciones, relatos, cuestionarios, resumen oral, etc.

La escuela, como institución que aprende, deberá velar porque la lectura sea una actividad relevante en la que los alumnos se conviertan en lectores eficaces, pero también promover la lectura en los demás miembros de la comunidad educativa: que el Plan Lector se extienda para todos. Sin embargo, el mayor reto recae en los docentes (de Educación Primaria) ya que deben lograr que cada uno de sus niños desarrolle con naturalidad y placer su capacidad lectora y al mismo tiempo construya su hábito lector.

Si tenemos un maestro que es amante de la lectura, o sea que es un lector habitual, ya podemos —en cierta forma - sentirnos tranquilos porque posiblemente él hará todo lo posible porque sus niños también sean lectores. Lo grave es, como suele ocurrir en el Perú, que justo los encargados de enseñar a leer, no leen. 


\section{La lectura incrementa la capacidad de concentración del niño}

Las costumbres se desarrollan a través de la práctica y coger el hábito de la lectura dará a tu hijo más facilidades para concentrarse y para prestar atención. La lectura le motivará a que pueda empezar y terminar una determinada tarea, como por ejemplo una determinada historia que está leyendo, y esto le empezará a crear un hábito que será muy importante en su desarrollo personal. El niño se beneficiará de este hábito no solo para su éxito académico, sino también para su futuro éxito profesional y personal.

Por otro lado, ¿sabías que ver demasiada televisión tiene un efecto perjudicial sobre el promedio de atención que tienen los niños y sobre su capacidad para concentrarse? La televisión es un medio que salta de un tema a otro constantemente con la esperanza de ganar y retener a los espectadores. Estos cambios constantes de información y de imágenes disminuyen la capacidad de concentración de los más pequeños. Si tus niños pasan muchas horas frente a la televisión, su capacidad de concentración tenderá a disminuir.

\section{La lectura desarrolla la capacidad de comunicación de los niños}

La lectura es fundamental en la vida de toda persona. Todos los días tenemos que leer carteles, señales de tránsito, informes, periódico, mensajes de correo electrónico, etiquetas de los alimentos y muchas cosas más. La realidad es que difícilmente podríamos funcionar en el mundo y en la civilización actual si no supiéramos leer.

Un niño lector, en relación a la comunicación, desarrolla: 
- La capacidad de escribir de manera correcta y entiende el poder de la palabra escrita.

- Una fuerte comprensión de lectura y un fuerte vocabulario.

- Su capacidad de expresarse de una forma mucho más segura, creativa, y de manera fácil. La lectura mejora la autoestima y la confianza en sí mismo.

- Su imaginación, curiosidad y su capacidad de pensar.

Los efectos que tiene la lectura en el desarrollo del niño son progresivos. Cuanto más lee, más utiliza la fonética para probar nuevas palabras y más podrá aprender acerca de lo que lee.

\section{La lectura hace volar la imaginación de los niños}

La lectura es un vehículo especialmente importante para hacer volar la imaginación de los más pequeños. A diferencia de la TV, que permite ver personajes y acontecimientos ya definidos en la lectura, es muy diferente, el libro cuenta una historia y deja que vayamos creando en la mente los escenarios, personajes, etc.

¿No nos ha pasado nunca que después de ver la película de un libro que te ha gustado mucho, esta te ha decepcionado? Esto ocurre por diferentes motivos. Uno de ellos es porque la película es mucho más corta y nunca puede ser tan rica en detalles como lo es el libro. Otro de los motivos es porque a menudo, las imágenes que vemos en la película no son como las habíamos imaginado al leer el libro. Los actores son más feos, más guapos, más gordos o más delgados de cómo los habíamos imaginados... El entorno, el escenario, el decorado, las expresiones, los sentimientos de los personajes tampoco son como lo habíamos imaginado... Y es normal que 
nos decepcione, ya que en nuestra mente habíamos imaginado el escenario y los personajes ideales para la trama del libro.

\section{La lectura crea un hábito con el que se adquirirán nuevos conocimientos}

Los primeros años de un niño son los más importantes ya que son los años en los que adquiere muchos de los hábitos que le acompañarán durante el resto de su vida.

Por este motivo, uno de los beneficios más importantes que tiene que a un niño le hayan leído desde pequeñito, es que ese niño será mucho más propenso a convertirse después en un adulto lector. El hábito de la lectura ayudará primero al niño y después al adulto en muchos ámbitos de su vida. Le ayudará en su etapa de estudiante, en su etapa profesional y también en su ocio, creándole un hábito que será muy importante para él o ella.

La lectura en voz alta personalizada es una buena ocasión para enseñar a los hijos sobre temas cotidianos. Afortunadamente, nuestros hijos escuchan y aprenden todos los días cosas nuevas en la escuela, pero un aula no debería ser el único lugar para dar respuesta a las preguntas y dudas que ellos tienen.

\section{La lectura refuerza la capacidad de aprendizaje}

Científicos, pediatras y educadores coinciden en que la lectura refuerza en los niños su voluntad de aprendizaje. También sostienen que leer a los niños es una de las principales formas de interesarlos por la lectura. Inculcar el amor por la lectura y alentar al niño a mantener vivo el deseo de leer será muy importante en el momento de su desarrollo, para constituirlos como sujetos más completos e inteligentes. 
Los niños que leen desde pequeños aprenden con mayor facilidad y rapidez que aquellos que no han tenido la posibilidad de disfrutar de los beneficios de la lectura. La lectura fomenta en los niños el desarrollo del lenguaje, su capacidad de escuchar, enriquecen su vocabulario, incrementan su capacidad de expresarse y aumentan su capacidad de concentración.

Por último, la lectura en voz alta personalizada es una buena ocasión para enseñar a tus hijos sobre temas cotidianos. Afortunadamente, nuestros hijos escuchan y aprenden todos los días cosas nuevas en la escuela, pero un aula no debería ser el único lugar para dar respuesta a las preguntas y dudas que tienen.

\section{La lectura mejora la coordinación de los más pequeños}

La lectura también proporciona oportunidades para el desarrollo físico y coordinación de los más pequeños: el simple hecho de dar la vuelta a una página cada vez que la lee, le ayuda a estimular la motricidad. Además, una rutina de lectura estimula los músculos de los ojos y afecta, debido a la actividad cerebral, la química de todo el cuerpo. También tiene un efecto estimulante sobre sentidos como la vista, el sonido, el tacto y el olfato.

\section{La lectura incrementa la probabilidad de éxito}

Pero ¿por qué fomentar la lectura en un niño es tan importante? Además de promover el desarrollo del lenguaje en los niños, los niños que leen o que están expuestos a la lectura también podrán desarrollar los hábitos necesarios para tener éxito en la escuela, éxito que se extenderá durante toda su vida.

Sin duda, los padres queremos lo mejor para nuestros hijos. Entonces debemos responder a unas cuantas preguntas simples: 
- ¿Queremos desarrollar la inteligencia de nuestros hijos?

- ¿Queremos promover un hábito en nuestro hijo que le ayudará a adquirir conocimientos, disfrutando además de ello?

- ¿Queremos reforzar un vínculo importante que tenemos con los niños e incrementar su autoestima?

- ¿Queremos que desarrolle su imaginación?

- ¿Queremos que mejore su capacidad de comunicación y su lenguaje?

- ¿Queremos ayudarle a desarrollar sus habilidades, hábitos y rasgos más comúnmente asociados con el éxito?

Si nos encontramos con respuestas afirmativas, deberíamos iniciar a los hijos en la lectura. Debemos abrir un libro y empezar a leerles a partir de hoy. Un simple objeto llamado libro ayudará a los hijos en numerosos aspectos de su vida. Y no olvidemos de que educar a nuestros hijos en la lectura es verdaderamente uno de los dones más preciosos que podremos otorgar a nuestros niños, que además nos agradecerán el resto de sus vidas. 


\section{ANEXOS \\ I. Diseño del Proyecto}

1. Proyecto: «Lee conmigo»

2. Objetivo: Estimular el proceso de lectoescritura de los niños con la participación de los padres de familia.

3. Destinatarios: Niños de 5 años del Nivel de Educación Inicial.

4. Duración: 20 semanas (5 meses)

5. Etapas:

- Etapa de preparación: 6 semanas

- Etapa de aplicación: 10 semanas

- Etapa de evaluación: 4 semanas

6. Organización:

- Coordinador

- Docente tutora

- Padres de familia

- Niños y niñas 
7. Matriz de actividades:

\begin{tabular}{|c|c|c|c|}
\hline Etapas: & Actividades & Recursos & Responsable \\
\hline \multirow{8}{*}{ 1. Preparación: } & $\begin{array}{l}\text { Elaboración del } \\
\text { Proyecto }\end{array}$ & & $\begin{array}{l}\text { Coordinador/ } \\
\text { Tutora }\end{array}$ \\
\hline & $\begin{array}{l}\text { Sensibilización a } \\
\text { los PPFF }\end{array}$ & $\begin{array}{l}\text { Información, hoja } \\
\text { de ruta, } \\
\text { encuesta }\end{array}$ & $\begin{array}{l}\text { Coordinador/ } \\
\text { Tutora }\end{array}$ \\
\hline & $\begin{array}{l}\text { Establecimiento } \\
\text { de criterios de } \\
\text { selección de libros. }\end{array}$ & & $\begin{array}{l}\text { Coordinador/ } \\
\text { Tutora }\end{array}$ \\
\hline & $\begin{array}{l}\text { Selección de } \\
\text { material de lectura } \\
\text { (libros) }\end{array}$ & $\begin{array}{l}\text { Libros diversos que } \\
\text { se ajusten a criterios } \\
\text { preestablecidos }\end{array}$ & $\begin{array}{l}\text { Asesor/Tutora/ } \\
\text { Padres }\end{array}$ \\
\hline & $\begin{array}{l}\text { Adquisición de } \\
\text { libros }\end{array}$ & Cuotas & $\begin{array}{l}\text { Comisión de } \\
\text { padres }\end{array}$ \\
\hline & $\begin{array}{l}\text { Capacitación a } \\
\text { padres }\end{array}$ & $\begin{array}{l}\text { Varios (multimedia, } \\
\text { libro, ficha, } \\
\text { artículo) }\end{array}$ & Asesor \\
\hline & $\begin{array}{l}\text { Capacitación a } \\
\text { tutora }\end{array}$ & $\begin{array}{l}\text { Estrategias para } \\
\text { la comprensión } \\
\text { lectora }\end{array}$ & Asesor \\
\hline & $\begin{array}{l}\text { Orientación a } \\
\text { niños }\end{array}$ & $\begin{array}{l}\text { Estimulación a la } \\
\text { lectoescritura }\end{array}$ & Tutora \\
\hline \multirow[b]{3}{*}{ 2. Aplicación: } & $\begin{array}{l}\text { Programación de } \\
\text { las lecturas }\end{array}$ & $\begin{array}{l}\text { Programa de } \\
\text { lecturas }\end{array}$ & Tutora \\
\hline & Lectura (en casa) & $\begin{array}{l}\text { Libros (10) } \\
\text { Colección } \\
\text { Viajerito-Bruño }\end{array}$ & Padres \\
\hline & $\begin{array}{l}\text { Comprensión } \\
\text { lectora (en } \\
\text { escuela) a través } \\
\text { de actividades } \\
\text { diversas: dibujos, } \\
\text { modelados, } \\
\text { cantos, poemas, } \\
\text { teatros, }\end{array}$ & $\begin{array}{l}\text { Colores, plastilinas, } \\
\text { papeles, cartulinas, } \\
\text { goma, objetos para } \\
\text { las escenificaciones, } \\
\text { etc. }\end{array}$ & Tutora \\
\hline \multirow[t]{2}{*}{ 3. Evaluación: } & $\begin{array}{l}\text { Evaluación } \\
\text { del Proyecto } \\
\text { para identificar } \\
\text { procesos, } \\
\text { fortalezas, } \\
\text { debilidades. }\end{array}$ & $\begin{array}{l}\text { Ficha de } \\
\text { observación, } \\
\text { encuesta }\end{array}$ & $\begin{array}{l}\text { Coordinador, } \\
\text { tutora } \\
\text { padres, } \\
\text { alumnos }\end{array}$ \\
\hline & Propuesta de mejoras & & Tutora/Padres \\
\hline
\end{tabular}




\section{Diseño del Taller de sensibilización}

1. Taller: Capacitación a padres y madres de familia

2. Proyecto: «Lee conmigo»

3. Destinatarios: Padres de familia de Educación Inicial 5 años

4. Programa:

Primera fecha:

a. Ficha para contestar:

- ¿Qué regalos sueles hacerle a tu hijo(a)?

- ¿Qué tiempo dispones para estar con tu hijo(a) cada día?

- ¿Por qué desearías que tu hijo sea un buen lector?

b. Discusión en parejas comparando respuestas.

c. Discusión en grupos de 4 y sacando conclusiones.

d. Exposición de cada representante de grupo.

Segunda fecha:

a. Lectura del texto: «Dé a su hijo el mejor regalo» (David Schwartz.

En Selecciones del Reader's Digest, octubre 1995

b. Opiniones.

c. Conclusiones.

Tercera fecha:

a. Taller: ¿Cuándo, dónde y cómo voy a leer con mi hijo(a)? Equipo:

Power Point y multimedia.

b. Entrega de los libros.

c. Preguntas.

Cuarta fecha:

a. Misión y compromiso

b. Recomendaciones finales. 


\section{Anexo 3}

\section{Con unos cuantos minutos al día, muy gratos por cierto... DÉ A SUS HIJOS UN REGALO PARA TODA LA VIDA ${ }^{3}$}

JIM TRELEASE ha dedicado los últimos 16 años de su vida a divulgar lo que considera el secreto mejor guardado de la educación actual. "Casi nadie me cree cuando me oye hablar de él por primera vez», dice. «Y esto ocurre por tres razones: en primer lugar, porque se trata de algo sencillo. En segundo lugar, porque es gratis. En tercer lugar, porque el niño lo disfruta. Por todo esto, ¿cómo no va a ser bueno?».

El público de esta noche, compuesto en su mayoría por maestros y padres jóvenes que se han congregado en el auditorio de una escuela primaria, ríe nerviosamente. «Sé lo que están pensando», prosigue Trelease. «El día tiene sólo 24 horas. Es cierto. Pero, ¿quién les dijo que ser padres es una actividad en la que se invierte poco tiempo?» Trelease insiste en que, por muy ocupados que estén, el alimento más importante que pueden dar a sus hijos, después de las caricias, es leerles en voz alta.

Y apoya sus palabras con hechos. Muchos estudios, entre ellos unos informes recientes del Centro para el Estudio de la Lectura y el Consejo Nacional de Maestros de Lengua Inglesa, confirman que leer a los niños les ayuda a ampliar su vocabulario, estimula su imaginación, prolonga el lapso de su atención, fomenta el desarrollo emocional y los introduce a las estructuras y los matices de la lengua. La lectura en voz alta constituye, en esencia, una invitación a aprender a leer.

Trelease se lamenta de que, con demasiada frecuencia, se condiciona a los alumnos de las escuelas primarias a asociar la lectura con el trabajo.

3 Por David Schwartz. En Selecciones del Reader’s Digest, octubre, 1995. 
«Nos hemos concentrado tanto en enseñar a los niños a leer que nos hemos olvidado de inculcarles el deseo de leer", observa.

Para que no quede duda sobre lo que está en juego, Trelease no vacila en afirmar: «La lectura es el factor social más importante de la vida actual. Cuanto más lee una persona, más inteligente se vuelve. Cuanto más inteligente se vuelve, más años dedica al estudio. Cuantos más años estudia, más dinero gana. Cuanto más dinero gana, mejor papel desempeñan sus hijos en la escuela. De modo que si se logra aficionar a un niño a la lectura, se influye no sólo en su futuro, sino también en el de la siguiente generación».

Trelease encontró su vocación por razones que no tuvieron que ver con el intelecto, sino con las emociones. En la época en que sus dos hijos, Elizabeth y Jamie, eran pequeños, él y su esposa, Susan, les dieron igual cantidad de libros que de comidas. "Les leí porque mi padre, a su vez, me leyó a mí», explica.

«Quería que ellos disfrutaran tanto como yo había disfrutado».

Durante su infancia, en el decenio de 1940, aún no se había borrado el recuerdo de la Depresión. «No tuvimos automóvil hasta que cumplí diez años, ni casa propia hasta que cumplí los 12», comenta Trelease. "Pero no hubo un tiempo en que no hubiéramos estado suscritos a varias revistas y a dos diarios». No se acuerda que haya pasado un día de su niñez sin que su padre le leyera algo.

Después de titularse en la Universidad de Massachusetts, Trelease empezó a trabajar como reportero en la cercana ciudad de Springfield. Luego, en 1967, una maestra de cuarto año de primaria lo invitó a su salón de clases a dar una plática sobre su profesión. Trelease se divirtió tanto que, un tiempo después, ya estaba dando 40 charlas gratuitas por ańo en las escuelas de la ciudad. 
Un día, cuando estaba a punto de salir de un aula, sus ojos se posaron en un ejemplar de una novela que acababa de leerle a su hija.

- ¿Quién está leyendo esto? - inquirió. Tres nińas levantaron tímidamente la mano - ¿No les fascina?

Y durante los 45 minutos siguientes, él y los chicos estuvieron conversando sobre libros.

«A partir de entonces, siempre aparté un rato para preguntarles a los chicos qué libros habían leído últimamente», explica.

"Con el tiempo comencé a percatarme de que leían cada vez menos, salvo en aquellos casos en que los maestros les leían en voz alta. Me pregunté si existiría alguna relación entre cuánto se les lee a los niños y cuánto quieren ellos leer por cuenta propia».

En las publicaciones profesionales sobre lectura, Trelease se encontró con muchas investigaciones que apoyaban su suposición. Por sus conversaciones con vecinos, parientes y amigos, supo que la mayoría de la gente consideraba la lectura en voz alta como el último recurso cuando sus hijos no querían dormirse. Quizá ello se debía a que, a estos padres, rara vez se les leyó cuando fueron pequeños.

«Las palabras que el niño escucha cuando se le lee son palabras que él podrá identificar después, cuando se tope con ellas en sus propias lecturas», dice Trelease. Para ilustrar esta idea, cita el primer párrafo de The Enormous Crocodile (Un cocodrilo enorme), de Roald Dahl. «Dos cocodrilos estaban metidos en el agua, y apenas asomaban la cabeza. Uno era enorme. El otro no era tan grande». Supongamos que el niño no conoce la palabra enorme. ¿Cómo la aprenderá más fácilmente: escuchándola como parte de la trama de un cuento o viéndola escrita en una tarjeta de vocabulario, sin un contexto que le dé significado? Recuerden que si el nińo nunca ha escuchado la palabra, jamás la usará. Y si nunca la ha escuchado ni usado, le será difícil leerla cuando se encuentre con ella». 
MARIO AMORÓS TERRONES

Trelease recomienda que se empiece a leer en voz alta a los niños lo más pronto posible. «¿Cuándo comenzó usted a hablarle a su hijo? Sin duda, el día en que nació. Si un nińo no es demasiado pequeño para que se le hable, tampoco es demasiado pequeńo para que se le lea». Así lo asegura la experiencia.

Al nacer su hija, a Marcia y Mark Thomas les regalaron un ejemplar del famoso libro de Trelease, The Read-Alaoud Handbook (Manual de lectura en voz alta). Estos padres tenían una razón especial para querer fomentar el desarrollo intelectural de Jennifer: la niña había nacido con el síndrome de Down. "Pensamos que si no le hacía bien, tampoco le haría mal», comenta Marcia, «así que la pusimos a una dieta de diez libros diarios». Cuando la pequeña tuvo que someterse a una intervención quirúrgica, sus padres grabaron libros en cintas para que las enfermeras se los reprodujeran. A los cinco años, Jennifer leía sola.

Hoy tiene diez años y cursa el cuarto año de primaria en una escuela para niños normales. Además, es una lectora voraz y tiene un vocabulario que una de sus maestras califica de «fenomenal».

A Trelease le da gusto que otras personas se dediquen a multiplicar sus esfuerzos. Mary Kay Bond oyó hablar por primera vez de «ese hombre que promueve la lectura en voz alta» a comienzos de los años ochenta. Entonces era una madre flamante, y ya acostumbraba a leer revistas de noticias a su bebé de tres meses, pese a la risa que ello provocaba en su familia.

Más adelante, Mary Kay y otras nueve madres del jardín de niños de su hijo se unieron para crear un programa basado en las ideas de Trelease. Organizaron un grupo de voluntarias que leyeran en las escuelas y dieran pláticas en los cursos para futuros padres. Consiguieron un subsidio para un programa de distribución de libros, con objeto de que todo niño nacido en su distrito por lo menos recibiera un ejemplar como obsequio de nacimiento. En 1992 el programa, llamado «Leamos en voz alta», se extendió a todo el estado. 
Cuando Lynne Waihee, esposa del ex gobernador de Hawai, oyó hablar a Jim Trelease, se sintió inspirada. No tardó en convencer a los clubes de Rotarios, las bibliotecas, las escuelas y a diversas empresas de su estado de que lanzaran la campaña «Léeme». El objetivo: asegurarse de que a todos los nińos hawaianos se les lea por lo menos diez minutos diarios. «Durante años, nuestro programa de alfabetización estuvo dirigido a la población adulta», explica Lynne, "pero nos dimos cuenta de que si fijábamos nuestra atención en criar a una generación de gente capaz de leer y escribir en lugar de querer componer a una que ya es analfabeta, tendríamos una probabilidad de éxito mucho mayor».

«Léeme» difunde su mensaje por medio de espacios publicitarios en radio y televisión. Además, todas las escuelas primarias y las bibliotecas de Hawai han recibido una bibliografía de libros infantiles recomendados y un vídeo de diez minutos sobre el porqué y el cómo de la lectura en voz alta.

Mientras tanto, Trelease sigue sembrando las semillas de la lectura. Se pasea por el auditorio de la escuela primaria, y habla sin dirigirse a nadie en particular. «Usted, señor, tuvo tiempo ayer de ver el partido de su equipo favorito de béisbol. Usted, señora, tuvo tiempo para salir de compras. Tuvo tiempo también de darse una escapada a la tienda de la esquina a comprar un billete de lotería, adquirir cigarrillos o rentar una videocinta. Tuvo tiempo de barrer las pelusas que había debajo del sofá. Pero, ¿nninguno de los dos tuvo tiempo de leer un libro a su hijo? Les aseguro sin temor a equivocarme que dentro de 20 años las pelusas seguirán debajo del sofá, pero su hijito ya no será pequeño».

El mensaje cala. Tras dos horas de conferencia, un centenar de personas regresan a sus hogares, donde duermen sus hijos. Y mańana, por razones que ignorarán, los pequeños escucharán a sus padres leerles, quizá por primera vez en ańos. 


\section{BIBLIOGRAFÍA}

Aliagas Marín, Cristina

2009 Aprendiendo a leer y a escribir con la canguro. Barcelona: Paidós.

Alliende G., Felipe y Mabel Condemarín G.

2002 La lectura: teoría, evaluación y desarrollo. Santiago de Chile: Editorial Andrés Bello.

Cassany, Daniel

2009 Para ser letrados. Voces y miradas sobre la lectura. Barcelona: Paidós. 2007 «Luces y sombras de la lectura en voz alta». Peonza, revista de literatura infantil y juvenil, N. 82, noviembre.

Cullinan, Bernice E.

1992 Léeme un cuento: desarrolle en sus niños el amor a la lectura. Edición especial. Hong Kong: Time Life.

Martín Peris, Ernesto

2004 «Qué significa trabajar en clase con tareas comunicativas?». redELE.

Disponible en <www.mepsyd.es/redele/revista/martin.shtml>.

SÁnChez Lihón, Danilo

1995 Promoción de la lectura. Lima: Instituto del libro y la lecturaINLEC. 
Sandoval, Constanza

2005 «El cuento infantil: una experiencia de lenguaje integral». ieRed, revista Electrónica de la Red de Investigación Educativa, Vol.1, N.2. Disponible en < http://revista.iered.org/v1n2/html/csandoval. html>.

SchWARTZ, David

1995 «Dé a su hijo el mejor regalo». Selecciones del Reader's Digest, octubre, p. xx.

Trelease, Jim

2010 Manual de la lectura en voz alta. Bogotá: Fundalectura.

\section{Enlaces de interés}

http://danilosanchezlihon.blogspot.com/

www.facebook.com/pages/Distribuidora-Navarrete/39939162 3932 ? $=a p p_{-} 10467688569 \& \mathrm{ref}=\mathrm{ts}$

http://paratuhijo.blogspot.com/

www.scribd.com/.../Doman-Glenn-J-Como-Ensenar-a-Leer-a-Su-Bebe www.mepsyd.es/redele/revista/martin.shtml 